\title{
Manufacturing workforce assessment using AHP and TOPSIS logic
}

\author{
AbdelhamidZAKI ${ }^{\# 1}$, Mohammed BENBRAHIM ${ }^{\# 2}$, Bahia BENCHEKROUN ${ }^{\# 3}$, GhassaneAYAD ${ }^{\# 4}$ \\ "Department of Industrial Engineering, Mohammadia School of Engineers, \\ Mohammed V University, BP 765, Agdal, Rabat, Morocco \\ ${ }^{1}$ zaki.hamid@yahoo.fr, \\ ²benbrahim@emi.ac.ma, \\ 3bahia@emi.ac.ma, \\ 4ghassane.ayad@gmail.com
}

\begin{abstract}
To perform a given activity by two individuals having the same qualification, the performanceof achievement varies, which introduces the concept of individual competence level. This article presents an assessment method of multi-skilled workforce. In this paper wewill discuss how to consider the differences and similarities between acquired level and required level. For a compound competence, the objective of our method is to present a quantified assessment method usingAHP technique and TOPSISlogic which allows calculating the degree of excellence in the use of all individual competencies in execution of all activities.
\end{abstract}

Keywords-Assessment,Individual competence, Performance, AHP, TOPSIS.

\section{INTRODUCTION}

Nowadays, the concept of individual competence takes an important place in manufacturing industry. Management methods of production resources have focused mainly on the management of material resources. [4]consider the company as: A system of production of goods and services whose performance resides in the control of the process of creating added value. And as a system of production of knowledge and competences which its competitiveness is based on the control of the process of capitalization of knowledge and competences development.

Thus, the competence management is integrated as a fundamental lever for the improvement of the enterprise performances.Competences management involvesa set of practices that aim to use and develop the competences of the individuals and teams in an optimal way, in order to achieve the mission of the enterprise and improve employee performance [1]. In addition, it aims to enhance the competitiveness of an enterprise as well as the mobilization and the employability of its employees [17]. According to [6], the general approach of competences management follows mainly three steps: firstly, to specify the required competences and identify the competences acquired; secondly, to evaluate individual and collective competences and finally, to elaborate strategies for the development of individual and collective competences.In this paper, we have focused on the problem of individual competence assessment. The assessment method must be based on operational tools for its effective implementation by users. In addition, it must be based on an analysis of not only the individual characteristics but also on the characteristics of the work situation [7].

The paper is structured as follows. In the next section, the problem description is given. Section 3 discusses the principle of the proposed assessment method. Section 4 discusses the characterization and prioritization of activities. Section 5contains details of thecharacterization of actors and weighting of each assessment criterion. Section 6discusses the proposed model for assessment of multi-skilled workforce using TOPSIS logic. In section 7 we present our conclusions.

\section{RESEARCH CONTEXT AND PROBLEM DESCRIPTION}

In this article, we will discuss the problem of assessing the individual performance level which is the manifestation of his/her competency. Thus, to measure the competence level we havechosen the use of tangible results revealing aspects of competence level. An individual is efficient when he/sheperforms activities with desired performance. The question is: are we talking about his/her performance or his/her competence? According to [19]: "Capable operators who have a good or a very good performance are considered very competent”.According to [16], competence is virtual whereas performance is observable. According to the same author "performance becomes competence (i.e. the individual is a subject of a social judgment, an inference of competence from the observation of a performance) when it respects the conditions of efficiency, reproducibility and regularity". Therefore, we can say that the individual competence assessment is a judgment of the performance of the obtained results performed by the worker. In [5], the authors have defined five elements that can be affected by the individual performance: the labor costs, the working speed, the efficiency, the quality of work and the tasks that the worker can perform. 
Some of the various techniques used to assess the individual competence are : descriptive assessment, conventional assessment scale; critical incident technique (CIT); repertory grid (RG); behaviorally anchored rating scales (BARS), management by objectives (MBO) ,etc. There are others models that use the linguistic assessments such as: The problem of evaluating the performance of intellectual capital [23], the problem of assessing knowledge management capacity [8]; problem of assignment under constraints of competences and preferences [10], etc.According to [3] and [22], the process of assessment is based on the difference between both the desired results and the achieved results. According to [18], the assessment by objectives is based on observable facts, which gives credibility and objectivity of the method. Our proposed method is based on the use of tangible results which allow us to provide a quantitative evaluation method.

Let us consider, for example, a production program to be carried out by an operator with medium level. After execution of the quantity demanded, we notice that the completion time exceeds the standard time (Fig. 1). Among the produced units there are non-compliant products and during production there were amounts of components which were handled improperly(Fig. 2). This additional time, non-compliant products and damaged components contribute tolosses for companies,these losses aredirectly related to the worker'sperformance.

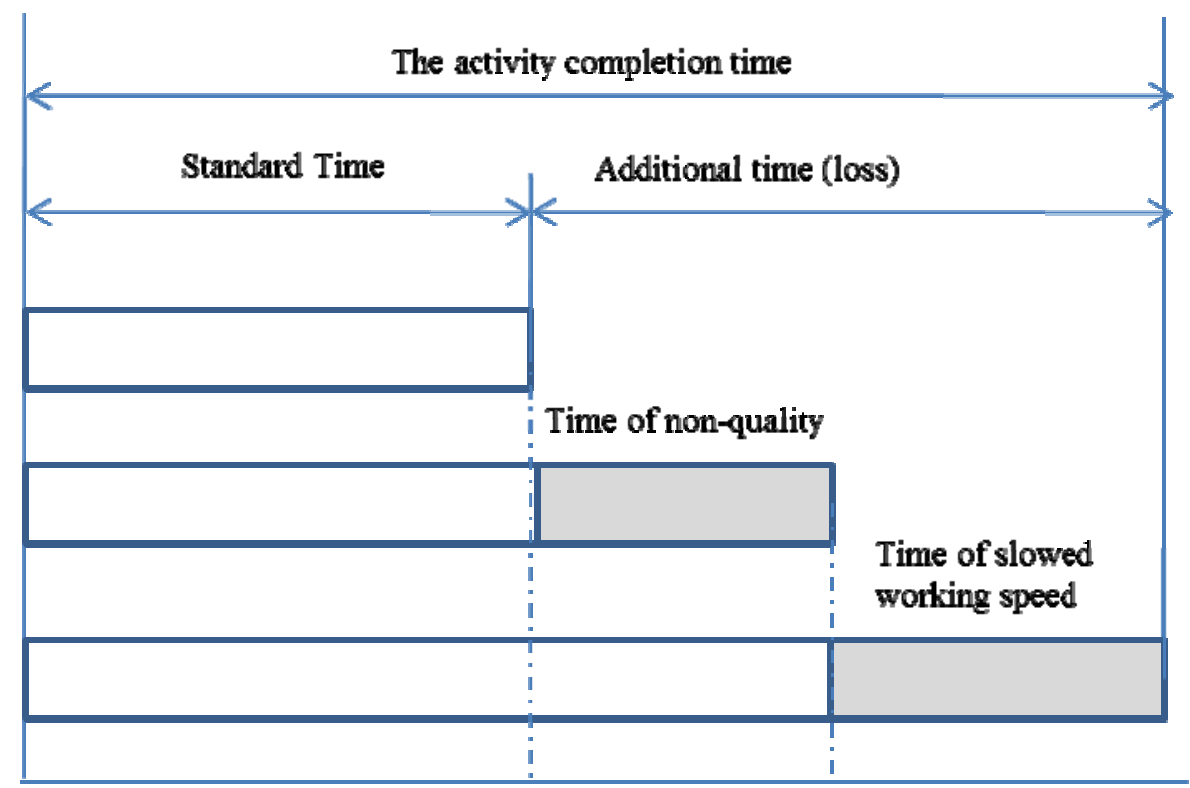

Fig. 1.Completion time compared to the standard time

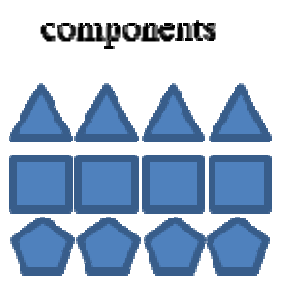

Product structure
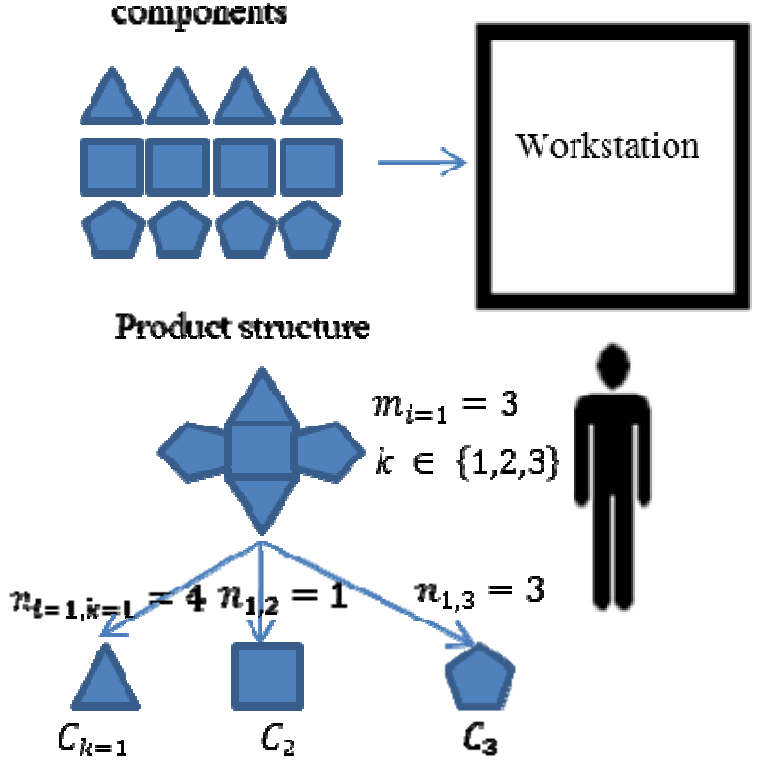

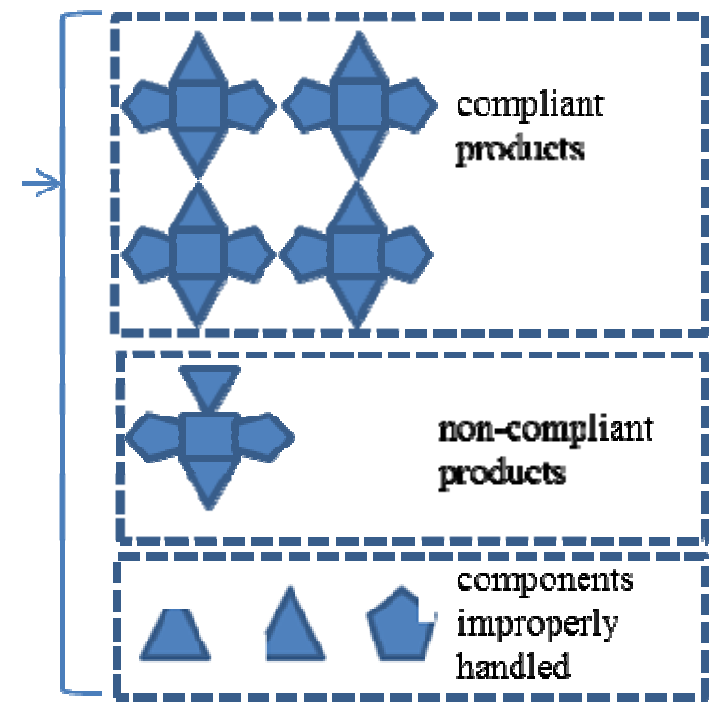

Fig. 2. The losses incurred 
In this article, we will define the problem of quantification of an individual's performance level of multiskilled workforces with high added value in a manufacturing sector. To properly assess the competence level of the workforces, the most criticalstep is to determine the relative importance between activities to be performed and the same thing between assessment criteria. According to [9]criteria must be weighted because not all criteria have the same importance.This paper presents an aggregated evaluation indicator allowing the decisionmaker to rank the production operators in an objective way.

\section{PRINCIPLE OF THE ASSESSMENT METHOD}

An activity is performed efficiently when it is performed within the allotted time, with good quality and with the respected numberf components or the quantity of the raw material used. To properly measure the individual competence level, it is important to have several evaluation criteria. The interest ofthis method isto helpthe decision maker to classify individuals. The classification may be carried by the use of advanced decision methods as that AHP (Analytical hierarchy process) and/or TOPSIS (Technique for order performance by similarity to ideal solution). In this paper, we proposean approach based onan evaluation process including AHP technique and TOPSIS logic, to assess theindividualperformance using theobserved differences between required level and acquired level. The following figure (Fig. 3) shows the different steps which are detailed below:

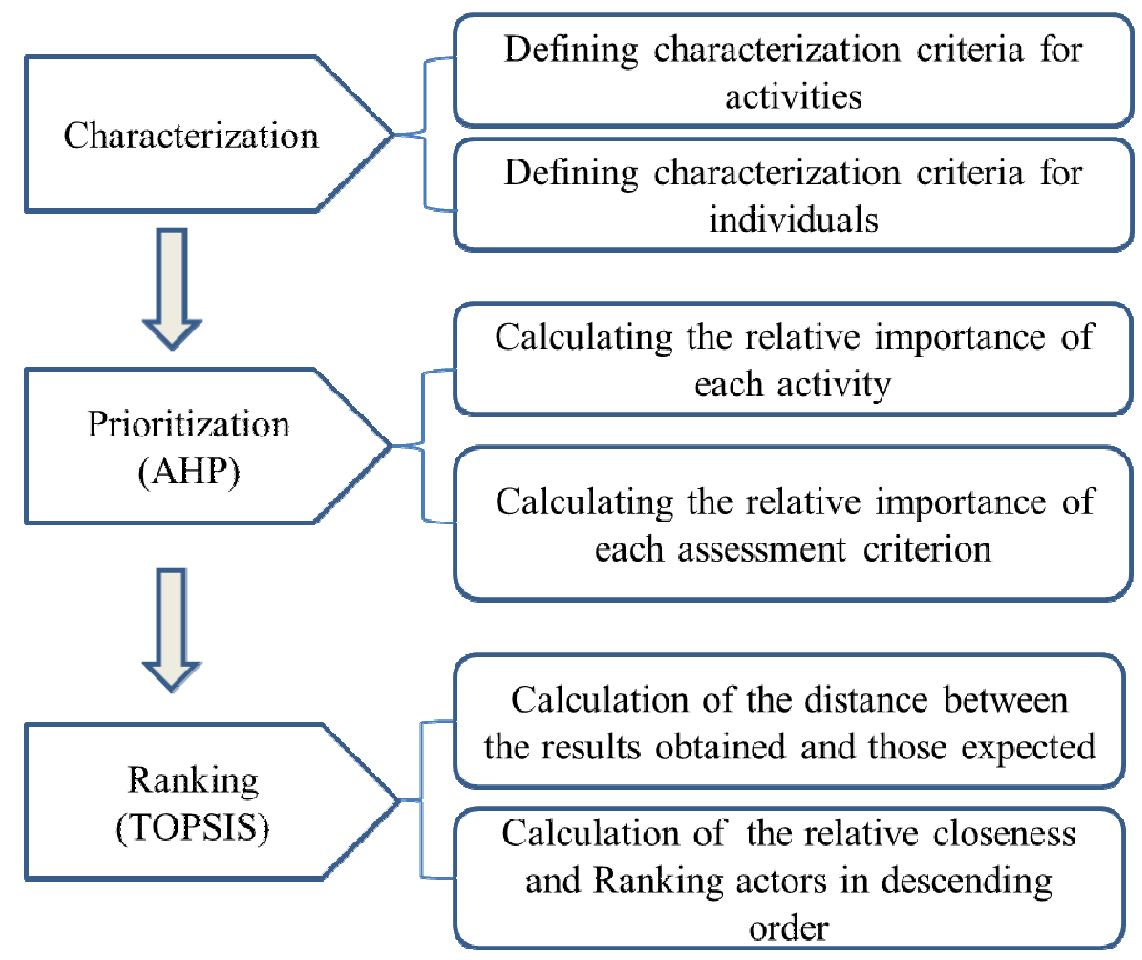

Fig.3. The steps of the assessment method

\section{CHARACTERIZATION AND PRIORITIZATION OF ACTIVITIES}

\section{A. Characterization of activities}

The characterization and the prioritization of activities depend on their importance and the context of the company. In this article we proposed to characterize the activities by their complexity of realization. We assumed that the complexity of carrying out an activity is based on four contextual factors as shown in Fig. 4.

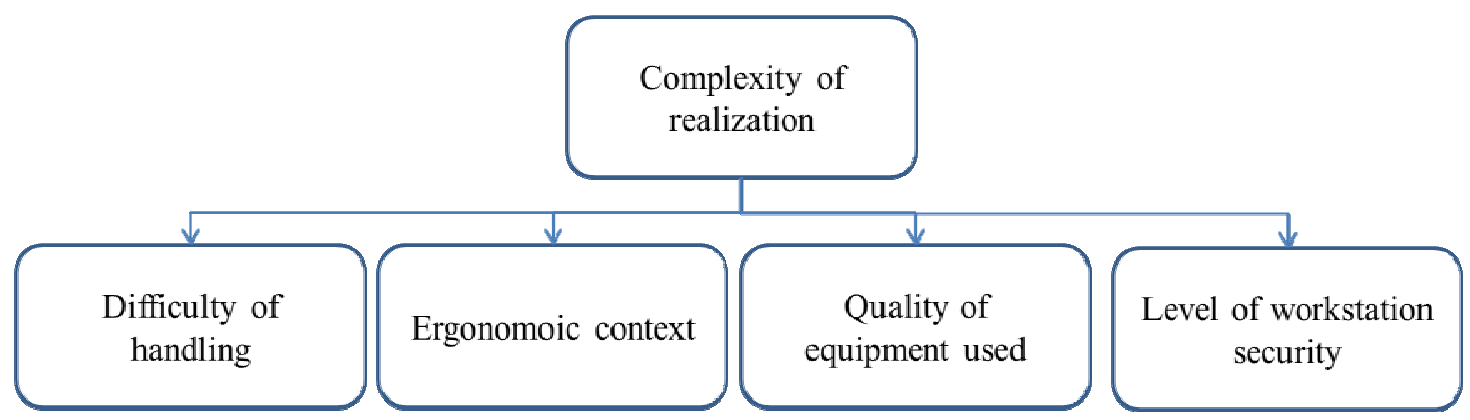

Fig.4. Characterization of activities 
Where,

-"Difficulty of handling"is related to the nature of the procedure followed (number of steps, number of parts to be assembled) and the quality of the raw material used (easy or difficult to process);

-“Ergonomic context”reflects the ergonomic working conditions (force exerted, posture, etc...);“Quality of equipment used"reflects the influence of the material used in performing an activity;

-"Level of workstation security"is related to the vigilance required to perform the requested activity.

In order to quantify the complexity of realization (C) in an objective manner, we have considered the value of (Ts : standard time) which indicatesthe theoretical time needed to perform a given activity taking into consideration the four contextual factors. So the value of (Ts) can reflect the degree of complexity of a given activity in a quantitative manner.

\section{B. Prioritization of activities}

To prioritize a given activity, we suggest using AHP method with a matrix that involves three criteria: Raw material cost, profit margin reflecting the importance of the activity and the complexity which reflects the degree of difficulty in performing the activity. Several methods have been proposed in the literature to describe the importance of alternatives. We choose the AHP method which can provide the decision maker with relevant information to assist him/her in choosing the best alternative or to rank a set of alternatives [21]. In this paper, the AHP method is used to rank activities in order to prioritize them. AHP method is based on four steps : The first step is the identification of criteria as shown in Fig. 5. Second step consists in pair-wise comparison for all criteria. The third step contains the determination of activities' weight and the last step is the ranking of activities. In this paper, to prioritize a given activity, we have adopted threecriteria: raw material cost (Cmp), profit margin (Pm) and complexity (C).

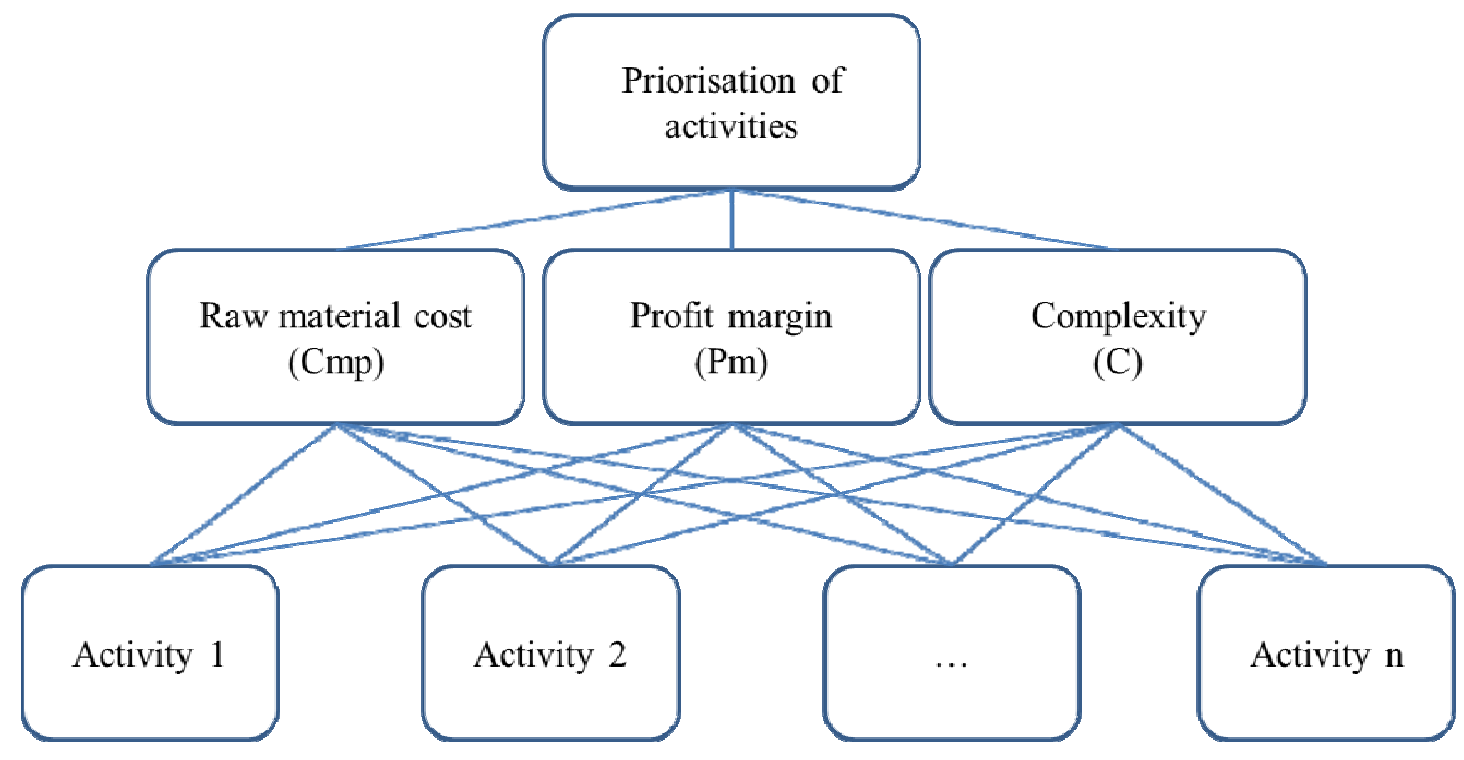

Fig. 5. Hierarchy of criteria

\section{1) Calculation of criteria weight:}

In this phase we will define the relative importance of each criterion. The relative importance varies from a criterion to another by reference to each activity. But, in our case we have three non-homogenous quantitative criteria (Cmp and Pm are both a cost criterion; C is not a cost criterion), we will first express the value of (C) as a cost.

As we have seen previously the complexity is expressed in term of (Ts), if we consider that the manufacturing cost $(C f)$ to produce one unit of a given activity (i) is equal to the multiplication of the average hourly rate (AHR) (expressed in money unit per hour) and the standard time ( $T s$ ) (expressed in hour) needed to produce one unit of the same activity, we get: $C f_{i(1 \text { unit) }}=A H R$. $T s_{i \text { (1 unit) }}$ with, (AHR) corresponds to the overall charges to be covered divided by the number of invoiced hours. We can deduce that the complexity (C) is directly related to (Cf) : when the complexity (C) increases, the value of (Ts) increases. Consequently, the manufacturing cost (Cf) increases. And we can also rapidly deduce that the combination of those three costs allows calculating the selling price (SP) as follows:

$$
S P_{i(1 \text { unit })}=C m p_{i(1 \text { unit })}+C f_{i(1 \text { unit })}+P m_{i(1 \text { unit })}
$$


Therefore, to determine the relative importance $\left(\alpha_{p}\right)$ of each criterion (p), we propose the following logic:

$$
\begin{gathered}
\alpha_{1}=\frac{\sum_{i=1}^{i=n} C m p_{i(1 \text { unit })}}{\sum_{i=1}^{i=n} S P_{i(1 \text { unit })}} \\
\alpha_{2}=\frac{\sum_{i=1}^{i=n} P m_{i(1 \text { unit })}}{\sum_{i=1}^{i=n} S P_{i(1 \text { unit })}} \\
\alpha_{3}=\frac{\sum_{i=1}^{i=n} A H R . T s_{i(1 \text { unit })}}{\sum_{i=1}^{i=n} S P_{i(1 \text { unit })}}
\end{gathered}
$$

As an illustrative example, we consider four alternatives A1, A2, A3 and A4; the three proposed criteria (raw material cost (Cmp), Profit margin (Pm) and Complexity (C)). We suppose the following input data shown in Table 1.

TABLE I. An example of input data concerning activities

\begin{tabular}{|c|c|c|c|c|c|c|}
\cline { 2 - 7 } \multicolumn{1}{c|}{} & Cmp (\$) & Pm (\$) & C (h) & AHR (\$/h) & Cf (\$) & SP (\$) \\
\hline A 1 & 30 & 40 & 0,50 & 40 & 20,0 & 90,0 \\
\hline A 2 & 25 & 30 & 0,42 & 40 & 16,7 & 71,7 \\
\hline A 3 & 40 & 30 & 0,17 & 40 & 6,7 & 76,7 \\
\hline A 4 & 25 & 20 & 0,75 & 40 & 30,0 & 75,0 \\
\hline Total & 120 & 120 & - & - & 73,3 & 313,3 \\
\hline
\end{tabular}

Thus, the criteria weight value is calculated as follow:

TABLE II. The criteria weight value

\begin{tabular}{|c|c|c|c|}
\cline { 2 - 4 } \multicolumn{1}{c|}{} & Cmp & Pm & C \\
\hline$\alpha_{p}$ & 0,383 & 0,383 & 0,234 \\
\hline
\end{tabular}

\section{2) Calculation of activities' weight}

In this segment, we proposed to use a pair-wise comparison based on ratios calculated from quantitative input data.We assume the input data shown in Table 1.

For instance, when we should express ajudgment when activity A2 is compared to activity A1 in terms of raw material cost. The corresponding comparison assumes the value of $\frac{C m p_{2}}{C m p_{1}}=1.2$. And, when activity A1 is compared to activity $\mathrm{A} 2$, the corresponding comparison assumes the value of $\frac{C m p_{1}}{C m p_{2}}=0.83$. A similar interpretation is true for the rest. The next step consists in calculating the relative importancefor each activity relative to each criterionas shown in Tables 3(a), 3(b) and 3(c).

For the first criterion "raw material cost (Cmp)", the judgment matrix with the pair-wise comparisons is calculated as follow (2):

$$
\left[a_{i j}\right]=\left[\begin{array}{cccc}
1 & C m p_{1} / C m p_{2} & \cdots & C m p_{1} / C m p_{n} \\
\mathrm{Cmp}_{2} / C m p_{1} & \cdot & \ddots & C m p_{2} / C m p_{n} \\
\vdots & \cdot & \ddots & \vdots \\
C m p_{n} / C m p_{1} & C m p_{n} / C m p_{2} & \cdots & 1
\end{array}\right]
$$

\begin{tabular}{|c|c|c|c|c|c|c|c|c|c|}
\hline & \multicolumn{4}{|c|}{$a_{i j}$} & \multicolumn{4}{|c|}{$r_{i j}$} & \multirow{2}{*}{$w_{i p}$} \\
\hline & A1 & A2 & A3 & A4 & A1 & A2 & A3 & A4 & \\
\hline A1 & 1,00 & 1,20 & 0,75 & 1,20 & 0,25 & 0,25 & 0,25 & 0,25 & 0,25 \\
\hline A2 & 0,83 & 1,00 & 0,63 & 1,00 & 0,21 & 0,21 & 0,21 & 0,21 & 0,21 \\
\hline A3 & 1,33 & 1,60 & 1,00 & 1,60 & 0,33 & 0,33 & 0,33 & 0,33 & 0,33 \\
\hline A4 & 0,83 & 1,00 & 0,63 & 1,00 & 0,21 & 0,21 & 0,21 & 0,21 & 0,21 \\
\hline Sum & 4,00 & 4,80 & 3,00 & 4,80 & 1,00 & 1,00 & 1,00 & 1,00 & 1,00 \\
\hline
\end{tabular}

TABLE III (a). Criteria pair-wise comparison matrix for raw material cost (Cmp) 
Where,

$$
\begin{aligned}
& r_{i j}=\frac{a_{i j}}{\sum_{i=1}^{n} a_{i j}} \quad \forall j \in N \\
& w_{i p}=\frac{\sum_{i=1}^{n} r_{i j}}{n} \quad \forall p \in O
\end{aligned}
$$

For the second criterion "Profit margin (Pm)", the judgment matrix with the pair-wise comparisons is calculated as follow (4):

$$
\left[a_{i j}\right]=\left[\begin{array}{cccc}
1 & \mathrm{Pm}_{1} / \mathrm{Pm}_{2} & \cdots & \mathrm{Pm}_{1} / \mathrm{Pm}_{n} \\
\mathrm{Pm}_{2} / \mathrm{Pm}_{1} & \cdot & \ddots & \mathrm{Pm}_{2} / \mathrm{Pm}_{n} \\
\vdots & \cdot & \ddots & \vdots \\
\mathrm{Pm}_{n} / \mathrm{Pm}_{1} & \mathrm{Pm}_{n} / \mathrm{Pm}_{2} & \cdots & 1
\end{array}\right]
$$

TABLE III (b). Criteria pair-wise comparison matrix for profit margin (Pm)

\begin{tabular}{|c|c|c|c|c|c|c|c|c|c|}
\hline & \multicolumn{4}{|c|}{$a_{i j}$} & \multicolumn{4}{|c|}{$r_{i j}$} & \multirow{2}{*}{$w_{i p}$} \\
\cline { 2 - 10 } & A1 & A2 & A3 & A4 & A1 & A2 & A3 & A4 & \\
\hline A1 & 1,00 & 1,33 & 1,33 & 2,00 & 0,33 & 0,33 & 0,33 & 0,33 & 0,33 \\
\hline A2 & 0,75 & 1,00 & 1,00 & 1,50 & 0,25 & 0,25 & 0,25 & 0,25 & 0,25 \\
\hline A3 & 0,75 & 1,00 & 1,00 & 1,50 & 0,25 & 0,25 & 0,25 & 0,25 & 0,25 \\
\hline A4 & 0,50 & 0,67 & 0,67 & 1,00 & 0,17 & 0,17 & 0,17 & 0,17 & 0,17 \\
\hline Sum & 3,00 & 4,00 & 4,00 & 6,00 & 1,00 & 1,00 & 1,00 & 1,00 & 1,00 \\
\hline
\end{tabular}

For the third criterion "complexity (C)", the judgment matrix with the pair-wise comparisons is calculated as follow (5):

$$
\left[a_{i j}\right]=\left[\begin{array}{cccc}
1 & T s_{1} / T s_{2} & \cdots & T s_{1} / T s_{n} \\
T s_{2} / T s_{1} & \cdot & . & T s_{2} / T s_{n} \\
\vdots & . & \ddots & \vdots \\
T s_{n} / T s_{1} & T s_{n} / T s_{2} & \cdots & 1
\end{array}\right]
$$

TABLE III (c). Criteria pair-wise comparison matrix for complexity (C)

\begin{tabular}{|c|c|c|c|c|c|c|c|c|c|}
\hline & \multicolumn{4}{|c}{$a_{i j}$} & \multicolumn{4}{c|}{$r_{i j}$} & \multirow{2}{*}{$w_{i p}$} \\
\cline { 2 - 9 } & A1 & A2 & A3 & A4 & A1 & A2 & A3 & A4 & \\
\hline A1 & 1,00 & 1,20 & 3,00 & 0,67 & 0,27 & 0,27 & 0,27 & 0,27 & 0,27 \\
\hline A2 & 0,83 & 1,00 & 2,50 & 0,56 & 0,23 & 0,23 & 0,23 & 0,23 & 0,23 \\
\hline A3 & 0,33 & 0,40 & 1,00 & 0,22 & 0,09 & 0,09 & 0,09 & 0,09 & 0,09 \\
\hline A4 & 1,50 & 1,80 & 4,50 & 1,00 & 0,41 & 0,41 & 0,41 & 0,41 & 0,41 \\
\hline Sum & 3,67 & 4,40 & 11,00 & 2,44 & 1,00 & 1,00 & 1,00 & 1,00 & 1,00 \\
\hline
\end{tabular}

\section{3) Ranking of activities}

The relative importance of eachcriterionis determined previously using pair-wise comparisons. And the activities are compared with each other in terms of each criterion. The final priorities denoted by $\varphi_{i}$ are determined according to the following formula (6):

$$
\varphi_{i}=\sum_{l=1}^{l=p} w_{i p} \alpha_{p}, \quad \forall i \in N
$$

The previous priority vectors resulting from the previous pair-wise matrixes are used to form the entries of the decision matrix. The final priorities are calculated according to formula (8). Table 4 illustrates the global weights of activities. 
TABLE IV. The global weights of activities

\begin{tabular}{|c|c|c|c|c|}
\cline { 2 - 4 } \multicolumn{1}{c|}{} & Cmp & Pm & C & \multirow{2}{*}{$\varphi_{i}$} \\
\cline { 2 - 4 } \multicolumn{1}{c|}{} & $\alpha_{1}=0,383$ & $\alpha_{2}=0,383$ & $\alpha_{3}=0,234$ & \\
\hline A1 & $w_{11}=0,25$ & 0,33 & $w_{13}=0,27$ & 0,287 \\
\hline A2 & 0,21 & 0,25 & 0,23 & 0,229 \\
\hline A3 & 0,33 & 0,25 & 0,09 & 0,245 \\
\hline A4 & $w_{41}=0,21$ & 0,17 & $w_{43}=0,41$ & 0,239 \\
\hline
\end{tabular}

\section{CHARACTERIZATION OF ACTORS AND WEIGHTING OF EACH ASSESSMENT CRITERION}

\section{A. Characterization of actors}

The performing of a given activity by an individual requires mobilizing individual competencies which reflectthe techniques used to solve problems; processing, reasoning and behaviors related to the characteristics of the worker. The description and the assessment of these elements are difficult. To overcome this difficulty, we have proposed to characterize them in terms of tangible results.Thus, we can say that a task is performed efficiently when it is done within the allotted time, with good quality and the respected theoreticalnumber of components or thetheoretical quantity of raw material needed to be used. In this paper, we haveadopted the three evaluation criteria proposed by [26]as illustrated in Fig. 6.with a modification of the third criterion.

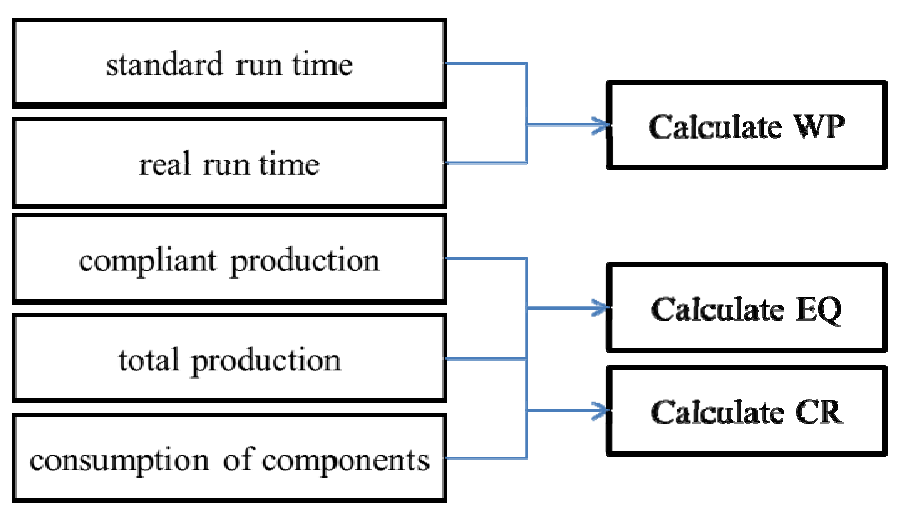

Fig. 6.The three evaluation criteria

In the manufacturing industry, each operator masters one or more activities. We can say that a given activity is performed efficiently when it is done within the allotted time, with good quality and with respect of the number of components set by the bill material file. In this work, we adopted the actors' characterizations discussed by [26]. Therefore, we express a worker's efficiency through three indicators: The first indicator $\left(\mathrm{WP}_{\mathrm{ij}}\right)$ is the work performance of the operator $(\mathrm{j})$ demonstrated when performing the activity (i).

$$
\mathrm{WP}_{\mathrm{ij}}=\frac{\operatorname{Ts}\left(Q p_{\mathrm{ij}}\right)}{\operatorname{Tr}\left(Q p_{\mathrm{ij}}\right)}
$$

With,

$Q p_{i j}$ : The planned quantity of activity (i) assigned to be done by the operator (j);

$\operatorname{Ts}\left(\mathrm{Qp}_{\mathrm{ij}}\right)$ : The standard time required to execute $Q p_{i}$;

$\operatorname{Tr}\left(Q p_{i j}\right)$ : The run time spent in executing $Q p_{i}$.

The second indicator $\left(E Q_{i j}\right)$ is the execution quality of the operator $(j)$ demonstrated when performing the activity (i).

$$
\mathrm{EQ}_{\mathrm{ij}}=\frac{\mathrm{Qd}_{\mathrm{ij}}}{\mathrm{Q}_{\mathrm{pij}}}
$$

With,

$\mathrm{Qd}_{\mathrm{ij}}$ : Compliant production of activity (i) produced by operator (j);

$\mathrm{Qp}_{\mathrm{ij}}$ : Total production of activity (i) produced by operator (j) (The planned quantity).

The third evaluation indicator $\left(\mathrm{CR}_{\mathrm{ij}}\right)$ is defined as the ratio between the total production carried out by the worker and the quantity of raw material used (Fig. 1.): 


$$
\mathrm{CR}_{\mathrm{ij}}=\left[\prod_{\mathrm{k}=1}^{\mathrm{k}=m_{i}} \mathrm{CR}_{\mathrm{kj}}\right]^{1 / m_{i}}=\mathrm{Qp}_{\mathrm{ij}} \cdot\left[\prod_{\mathrm{k}=1}^{\mathrm{k}=m_{i}} \frac{\mathrm{n}_{\mathrm{ik}}}{\mathrm{Qc}_{\mathrm{ijk}}}\right]^{1 / m_{i}}
$$

With,

$m_{i}$ : Number of components required to produce one unit of the activity (i);

$\mathrm{k}$ : Index of component;

$n_{i k}$ : Number of the component ( $\mathrm{k}$ ) required to produce one unit of the activity (i);

$Q c_{i j k}$ : The amount of component (k) consumed by the operator $(\mathrm{j})$ to produce $\left(\mathrm{Qp}_{\mathrm{i}}\right)$.

\section{B. Calculation of the degree of importance of each assessment criterion}

For the weighting of the three adopted sub-criteria (WP, EQ and CR), which reflect the individual performance, we have used the AHP technique. In the same manner as weighting activities, we proposed to use a pair-wise comparison based on ratios calculated from quantitative. To avoid subjectivity and in order to compare the different criteria in a quantitative way, we will determine the relationships between the three criteria and the different production costs (manufacturing cost, cost of non-quality and cost of waste).In this section, we will formulate the extra cost resulting from the assignment of a given activity (i) to a given operator (j) whose initial performance is not optimal. The demonstration presentsthree costs: the first one contains the extra cost due to additional time related to the working speed; the second one discussesthe extra cost due to noncompliant products, the third one isthe extra cost due to the loss of components which are improperly handled.

1) First cost due to the additional time

If the work performance (WP) is less than 1, this means there is an extra time in addition to the standard time. The extra time (Ta) is defined as the difference between the standard time (Ts) required achieving a given activity and the real time (Tr) spent on its achievement. So, there is an extra cost resulting from the assignment of a given activity (i) to a given operator (j) whose work performance is (WP). The extra time (Ta) to produce the quantity demanded $\left(Q d_{i}\right)$ is defined as:

$$
\operatorname{Ta}\left(Q d_{i}\right)=\left(1-W P_{\mathrm{i}}\right) \cdot \operatorname{Tr}\left(Q d_{i}\right)
$$

Let,

$$
\operatorname{Ts}\left(Q d_{i}\right)=\operatorname{Ts}_{i(1 \text { unit })} \cdot Q p_{i}=\operatorname{Ts}_{i(1 \text { unit })} \cdot \frac{Q d_{i}}{\mathrm{EQ}_{\mathrm{i}}}
$$

Replacing (11) in (7), we get:

$$
\operatorname{Tr}\left(Q d_{i}\right)=\frac{\operatorname{Ts}_{i(1 \text { unit })}}{\mathrm{WP}_{\mathrm{i}} \cdot \mathrm{EQ} Q_{\mathrm{i}}} Q Q d_{i}
$$

Substituting (12) in (10), the extra time due to the additional time is:

$$
\operatorname{Ta}\left(Q d_{i}\right)=\frac{1-\mathrm{WP}_{\mathrm{i}}}{\mathrm{WP}_{\mathrm{i}} \cdot \mathrm{EQ}_{\mathrm{i}}} \cdot \mathrm{Ts}_{i(1 \text { unit })} \cdot Q d_{i}
$$

The extra cost (Cat) due to the additional time (Ta)to produce (Qd)is equal to:

$$
\operatorname{Cat}\left(Q d_{i}\right)=\mathrm{Ta}\left(Q d_{i}\right) \cdot \mathrm{AHR}=\frac{1-\mathrm{WP}_{\mathrm{i}}}{\mathrm{WP}_{\mathrm{i}} \cdot \mathrm{EQ}_{\mathrm{i}}} \cdot \mathrm{Ts}_{i(1 \text { unit })} \cdot Q d_{i} \cdot \mathrm{AHR}
$$

Therefore,

$$
\operatorname{Cat}_{i(1 \text { unit })}=\frac{1-\mathrm{WP}_{\mathrm{i}}}{\mathrm{WP}_{\mathrm{i}} * \mathrm{EQ}_{\mathrm{i}}} \cdot \mathrm{Ts}_{i(1 \text { unit })} \cdot \mathrm{AHR}
$$

We can deduce that (Cat) is related to (WP), when (WP) decreases the value of (Cat) increases. As a result, the value of (Cat) is inversely proportional to (WP).

2) Second cost due to poor product:

If the execution quality (EQ) is less than 1 , this means there are wrong products. Assume that $\left(\mathrm{Cnq}\left(\mathrm{Qp} \mathrm{p}_{\mathrm{i}}\right)\right)$ corresponds to the cost of non-quality incurred when producing the planned quantity $\left(\mathrm{Qp}_{\mathrm{i}}\right)$ of the activity (i).

Let,

$$
\text { wrong product }\left(Q p_{i}\right)=\left(1-E Q_{i}\right) \cdot Q p_{i}=\left(1-E Q_{i}\right) \cdot \frac{Q d_{i}}{E Q_{i}}
$$


We considered that $\left(C r_{i(1 \text { unit })}\right)$ corresponds to the production cost and it's equal to the sum of the raw material cost $\left(C m p_{i(1 \text { unité })}\right)$ and the manufacturing cost $\left(C f_{i(1 \text { unit })}\right)$, so:

$$
\operatorname{Cnq}\left(Q p_{i}\right)=\frac{1-E Q_{i}}{E Q_{i}} \cdot Q d_{i} \cdot C r_{i(1 \text { unit })}
$$

Thus,

$$
C n q_{i(1 \text { unit })}=\frac{1-E Q_{i}}{E Q_{i}} \cdot C r_{i(1 \text { unit })}
$$

Therefore, we can deduce that when (EQ) decreases, (Cnq) will increase. As a result, the value of (Cnq) is inversely proportional to (EQ).

3) Third cost due to damaged components:

If the consumption ratio (CR) is less than 1 , this means there are damaged components due to improper use. Assume that $\left(\mathrm{C}_{\mathrm{d}}\left(\mathrm{Qp}_{\mathrm{i}}\right)\right)$ corresponds to the cost of "damaged components" incurred when producing the planned quantity $\left(\mathrm{Qp}_{\mathrm{i}}\right)$ of the activity (i) and $\left(\mathrm{Cmp}_{\mathrm{i}(1 \text { unit })}\right)$ corresponds to the raw material cost needed to produce one unit, with: $\mathrm{Cmp}_{\mathrm{i}(1 \text { unité })}=\sum_{\mathrm{k}=1}^{\mathrm{k}=\mathrm{m}} \mathrm{n}_{\mathrm{ik}}$. $\left.\mathrm{Cmp}_{\mathrm{ik}}\right)$, where $\left(\mathrm{Cmp}_{\mathrm{ik}}\right)$ corresponds to the purchase cost of components $(\mathrm{k})$, then $\left(\mathrm{C}_{\mathrm{d}}\left(\mathrm{Qp}_{\mathrm{i}}\right)\right)$ is:

$$
\begin{aligned}
& C_{d}\left(Q p_{i}\right)=\sum_{\mathrm{k}=1}^{m_{i}}\left(\frac{1-\mathrm{CR}_{\mathrm{ik}}}{\mathrm{CR}_{\mathrm{ik}}}\right) \cdot \mathrm{n}_{\mathrm{ik}} \cdot Q p_{i} \cdot \mathrm{Cmp}_{\mathrm{ik}} \\
& C_{d}\left(Q p_{i}\right)=\frac{Q d_{i}}{E Q_{i}} \cdot \sum_{\mathrm{k}=1}^{m_{i}}\left(\frac{1-\mathrm{CR}_{\mathrm{ik}}}{\mathrm{CR}_{\mathrm{ik}}}\right) \cdot \mathrm{n}_{\mathrm{ik}} \cdot \mathrm{Cmp}_{\mathrm{ik}}
\end{aligned}
$$

We propose the following hypothesis: $\mathrm{CR}_{\mathrm{ik}}=$ cte, $\forall \mathrm{k}$. So, $\mathrm{CR}_{\mathrm{i}}=\left[\prod_{\mathrm{k}=1}^{\mathrm{k}=\mathrm{m}_{\mathrm{i}}} \mathrm{CR}_{\mathrm{ik}}\right]^{1 / \mathrm{m}_{\mathrm{i}}}=\mathrm{CRi}_{\mathrm{k}}$

So:

Therefore:

$$
\mathrm{C}_{\mathrm{d}}\left(\mathrm{Qp}_{\mathrm{i}}\right)=\frac{\mathrm{Qd}_{\mathrm{i}}}{\mathrm{EQ}_{\mathrm{i}}} \cdot\left[\frac{\mathrm{Cmp}_{\mathrm{i}(1 \text { unit })}}{\mathrm{CR}_{\mathrm{i}}}-\mathrm{Cmp}_{\mathrm{i}(1 \text { unit })}\right]
$$

$$
\begin{gathered}
C_{d}\left(Q_{i}\right)=\frac{1-C_{i}}{E Q_{i} \cdot C_{i}} \cdot Q_{d_{i}} \cdot C p_{i}(1 \text { unit }) \\
C_{d_{i}(1 \text { unit })}=\frac{1-C_{i}}{E Q_{i} \cdot C R_{i}} \cdot C \operatorname{Cmp}_{i(1 \text { unit })}
\end{gathered}
$$

We can deduce that (Cd) is related to (CR), when (CR) decreases the cost (Cd) will increase. As a result, the value of (Cd) is inversely proportional to (CR).

For weighting the three sub-criteria (WP, EQ and CR) in an objective manner, we have used the three factors (Cat, Cnq and Cd) because they are homogeneous and they are all inversely proportional to the three evaluation criteria. As an illustrative example we assume the following input data shown in Table 5.

TABLE V. Quantitative input data (Example)

\begin{tabular}{|c|c|c|c|c|c|c|}
\cline { 2 - 7 } \multicolumn{1}{c|}{} & WP $_{\text {average }}$ & $E Q_{\text {average }}$ & CR $_{\text {average }}$ & Cat $_{(1 \text { unit })}$ & Cnq $_{(1 \text { unit })}$ & $C_{d_{(1 \text { unit })}}$ \\
\hline A 1 & 0,8 & 0,95 & 0,92 & 5,3 & 2,6 & 2,7 \\
\hline A 2 & 0,9 & 0,92 & 0,87 & 2,0 & 3,6 & 4,1 \\
\hline A 3 & 0,78 & 0,9 & 0,9 & 2,1 & 5,2 & 4,9 \\
\hline A 4 & 0,85 & 0,95 & 0,94 & 5,6 & 2,9 & 1,7 \\
\hline
\end{tabular}

For instance, when we express a judgment where (WP) is compared to (EQ) by reference to the activity (A1), the corresponding comparison assumes the value of $\frac{C a t_{1}}{C n q_{1}}=2.05$. And, when (EQ) is compared to (WP), the corresponding comparison assumes the value of $\frac{C n q_{1}}{C a t_{1}}=0.49$. A similar interpretation is true for the other comparisons.

The next step is to extract the relative importance of each assessment criterion (WP, EQ and CR) by reference to each activity. Tables 6(a), 6(b), 6(c) and 6(d) represent comparison matrixes of the three criterions respectively for the four activities. 
For the first activity (A1), the judgment matrix with the pair-wise comparisons is calculated as follows(23):

$$
\left[a_{i j}\right]=\left[\begin{array}{ccc}
1 & \mathrm{Cat}_{1} / \mathrm{Cnq}_{1} & \mathrm{Cat}_{1} / \mathrm{Cd}_{1} \\
\mathrm{Cnq}_{1} / \mathrm{Cat}_{1} & 1 & C n q_{1} / C d_{1} \\
\mathrm{Cd}_{1} / \mathrm{Cat}_{1} & C d_{1} / C n q_{1} & 1
\end{array}\right]
$$

TABLE VI (a). Criteria pair-wise comparison matrix for Activity 1

\begin{tabular}{|c|c|c|c|c|c|c|c|}
\hline \multirow{2}{*}{ A 1 } & \multicolumn{3}{|c|}{$a_{i j}$} & \multicolumn{3}{|c|}{$r_{i j}$} & \multirow{2}{*}{$\omega_{i c}$} \\
\cline { 2 - 7 } & WP & EQ & CR & WP & EQ & CR & \\
\hline WP & 1,00 & 2,04 & 1,96 & 0,50 & 0,50 & 0,50 & 0,50 \\
\hline EQ & 0,49 & 1,00 & 0,96 & 0,25 & 0,25 & 0,25 & 0,25 \\
\hline CR & 0,51 & 1,04 & 1,00 & 0,25 & 0,25 & 0,25 & 0,25 \\
\hline total & 2,00 & 4,08 & 3,93 & 1,00 & 1,00 & 1,00 & 1,00 \\
\hline
\end{tabular}

In the same way, we develop the three comparison matrix for the others activities:

TABLE VI (b). Criteria pair-wise comparison matrix for Activity 2

\begin{tabular}{|c|c|c|c|c|c|c|c|}
\hline \multirow{2}{*}{ A 2} & \multicolumn{3}{|c|}{$a_{i j}$} & \multicolumn{3}{|c|}{$r_{i j}$} & \multirow{2}{*}{$\omega_{i c}$} \\
\hline & WP & EQ & CR & WP & EQ & CR & \\
\hline WP & 1,00 & 0,56 & 0,49 & 0,21 & 0,21 & 0,21 & 0,21 \\
\hline EQ & 1,80 & 1,00 & 0,88 & 0,37 & 0,37 & 0,37 & 0,37 \\
\hline CR & 2,05 & 1,14 & 1,00 & 0,42 & 0,42 & 0,42 & 0,42 \\
\hline total & 4,85 & 2,69 & 2,37 & 1,00 & 1,00 & 1,00 & 1,00 \\
\hline
\end{tabular}

TABLE VI (c). Criteria pair-wise comparison matrix for Activity 3

\begin{tabular}{|c|c|c|c|c|c|c|c|}
\hline \multirow{2}{*}{ A 3} & \multicolumn{3}{|c|}{$a_{i j}$} & \multicolumn{3}{|c|}{$r_{i j}$} & \multirow{2}{*}{$\omega_{i c}$} \\
\hline & WP & EQ & CR & WP & EQ & CR & \\
\hline WP & 1,00 & 0,40 & 0,43 & 0,17 & 0,17 & 0,17 & 0,17 \\
\hline EQ & 2,48 & 1,00 & 1,06 & 0,43 & 0,43 & 0,43 & 0,43 \\
\hline CR & 2,33 & 0,94 & 1,00 & 0,40 & 0,40 & 0,40 & 0,40 \\
\hline total & 5,81 & 2,35 & 2,49 & 1,00 & 1,00 & 1,00 & 1,00 \\
\hline
\end{tabular}

TABLE VI (d). Criteria pair-wise comparison matrix for Activity 4

\begin{tabular}{|c|c|c|c|c|c|c|c|}
\hline \multirow{2}{*}{ A 4 } & \multicolumn{3}{|c|}{$a_{i j}$} & \multicolumn{3}{c|}{$r_{i j}$} & \multirow{2}{*}{$\omega_{i c}$} \\
\cline { 2 - 7 } & WP & EQ & CR & WP & EQ & CR & \\
\hline WP & 1,00 & 1,93 & 3,29 & 0,55 & 0,55 & 0,55 & 0,55 \\
\hline EQ & 0,52 & 1,00 & 1,71 & 0,28 & 0,28 & 0,28 & 0,28 \\
\hline CR & 0,30 & 0,59 & 1,00 & 0,17 & 0,17 & 0,17 & 0,17 \\
\hline total & 1,82 & 3,52 & 6,00 & 1,00 & 1,00 & 1,00 & 1,00 \\
\hline
\end{tabular}

The Table 7 summarizes the calculation made previously:

TABLE VII. Relative importance of assessment criterion

\begin{tabular}{|c|c|c|c|c|}
\hline$\omega_{i c}$ & A1 & A2 & A3 & A4 \\
\hline WP & $\omega_{11}=0,50$ & 0,21 & 0,17 & $\omega_{41}=0,55$ \\
\hline EQ & $\omega_{12}=0,25$ & 0,37 & 0,43 & $\omega_{42}=0,28$ \\
\hline CR & $\omega_{13}=0,25$ & 0,42 & 0,40 & $\omega_{43}=0,17$ \\
\hline
\end{tabular}




\section{THE PROPOSED MODEL FOR ASSESSMENT OF MULTI-SKILLED WORKFORCE USING TOPSIS LOGIC}

TOPSIS (Technique for order performance by similarity to ideal solution) [11] is a practical and useful technique for ranking and selection of a number of alternatives through distance measures. [11]further proposes that the ranking of alternatives will be based on the shortest distance from the positive ideal solution and the farthest from the negative ideal solution. It originates from the concept of a displaced ideal point from which the compromise solution has the shortest distance [2] [27]. TOPSIS has been successfully applied to various areas such as transportation [12], product design [13], manufacturing [15], plant location analysis [24], etc.In our case we have used the TOPSIS logic for order workers according to their relative closeness, and to provide an aggregated evaluation.The major weaknesses of TOPSIS technique are in not providing for weight elicitation, and consistency checking for judgments [20]. Tomake an objective assessment, we suggest an integrated approach that simultaneously uses the AHP technique for weighting and TOPSIS logic for ranking.

For TOPSIS technique, a decision matrix is required at the beginning of the process. The decision matrix contains competitive alternatives (activities), with their attributes' ratings. Originally TOPSIS utilizes Euclidean distances; the best alternative should be at the shortest distance from the ideal solution and the farthest distance from the anti-ideal solution.The detailed procedure is illustrated with an example in the following sections.

\section{A. Construct judgment matrix}

The structure of the matrix can be expressed as shown in Table 8: where $O p_{j}$ denotes the operators $(\mathrm{j}), j \in M$; $A_{i}$ denotes activity (i), $i \in N ; A C_{c}$ represents sub-criterion c , $c \in L . v_{i k j}$ indicates the performance rating of operator $\left(O p_{j}\right)$ with respect to activity $\left(A_{i}\right)$ and assessment criterion $\left(A C_{c}\right)$. The performance rating is calculated using the three formulas (7), (8) and 9.

TABLE VII.Judgment matrix with performance rating

\begin{tabular}{|c|c|c|c|c|c|c|}
\hline$A_{i}$ & $A C_{c}$ & $T_{i c}$ & $O p_{1}$ & $O p_{2}$ & $O p_{3}$ & $O p_{4}$ \\
\hline \multirow{4}{*}{ A 1 } & WP & 0,9 & $v_{111}=0,86$ & 0,77 & 0,72 & $v_{114}=0,76$ \\
\cline { 2 - 7 } & EQ & 0,95 & 0,91 & 0,83 & 0,83 & 0,91 \\
\cline { 2 - 7 } & $\mathrm{CR}$ & 0,96 & 0,9 & 0,81 & 0,94 & 0,92 \\
\hline \multirow{3}{*}{ A 2 } & WP & 0,92 & 0,81 & 0,85 & 0,77 & 0,8 \\
\cline { 2 - 7 } & $\mathrm{EQ}$ & 0,98 & 0,83 & 0,9 & 0,93 & 0,9 \\
\hline & $\mathrm{CR}$ & 0,95 & 0,8 & 0,89 & 0,82 & 0,87 \\
\hline \multirow{3}{*}{ A 3 } & WP & 0,89 & 0,76 & 0,83 & 0,94 & 0,94 \\
\cline { 2 - 7 } & $\mathrm{EQ}$ & 0,97 & 0,87 & 0,8 & 0,89 & 0,86 \\
\hline \multirow{3}{*}{ A 4 } & $\mathrm{CR}$ & 0,9 & 0,8 & 0,82 & 0,88 & 0,85 \\
\cline { 2 - 7 } & $\mathrm{WP}$ & 0,85 & 0,93 & 0,79 & 0,78 & 0,81 \\
\cline { 2 - 7 } & $\mathrm{EQ}$ & 0,96 & 0,93 & 0,82 & 0,81 & 0,87 \\
\hline
\end{tabular}

B. Calculation of the degree of importance of each activity and each assessment criterion

Using pair-wise comparisons, the relative importance of each activity andassessment criterion was previously computed. The Table 9 summarizes the calculation made previously with: 
TABLE IX. Relative importance of each activity and assessment criterion

\begin{tabular}{|c|c|c|c|}
\hline$A_{i}$ & $\varphi_{i}$ & $A C_{c}$ & $\omega_{i c}$ \\
\hline \multirow{3}{*}{ A 1} & \multirow{3}{*}{0,287} & WP & 0,50 \\
\hline & & EQ & 0,25 \\
\hline & & CR & 0,25 \\
\hline \multirow{3}{*}{ A 2} & \multirow{3}{*}{0,229} & WP & 0,21 \\
\hline & & EQ & 0,37 \\
\hline & & CR & 0,42 \\
\hline \multirow{3}{*}{ A 3} & \multirow{3}{*}{0,245} & WP & 0,17 \\
\hline & & EQ & 0,43 \\
\hline & & CR & 0,40 \\
\hline \multirow{3}{*}{ A 4} & \multirow{3}{*}{0,239} & WP & 0,55 \\
\hline & & EQ & 0,28 \\
\hline & & CR & 0,17 \\
\hline
\end{tabular}

\section{Determination of the ideal levels and anti-ideal levels}

By analogy with the TOPSIS method, we choose for each activity the best and the worst performance rating as ideal and anti-ideal performance level.

$$
V_{i c}^{-}=\left\{v_{11}^{-}, \ldots, v_{1 l}^{-}, \ldots, v_{n l}^{-}\right\}
$$

Where:

$$
v_{i c}^{-}=\operatorname{Min}\left(v_{i c j}\right) \forall i \in N ; \forall c \in L
$$

And:

Where:

$$
V_{i c}^{+}=\left\{v_{11}^{+}, \ldots, v_{1 l}^{+}, \ldots, v_{n l}^{+}\right\}
$$

$$
v_{i c}^{+}=\left\{\begin{array}{c}
\operatorname{Max}_{i c}\left(x_{i c j}\right) \text { if } T_{i c}<\operatorname{Max}\left(v_{i c j}\right) \\
T_{i c} \text { if } T_{i c}>\operatorname{Max}\left(v_{i c j}\right)
\end{array} \forall i \in N ; \forall c \in L\right.
$$

The idea is to minimize the gap between the required performance level and the acquired performance level. The Table 10 summarizes the ideal and anti-ideal performance level.

TABLE X.Ideal levels and anti-ideal levels

\begin{tabular}{|c|c|c|c|}
\hline$A_{i}$ & $A C_{c}$ & $v_{i c}^{+}$ & $v_{i c}^{-}$ \\
\hline \multirow{3}{*}{ A 1 } & WP & 0,9 & 0,72 \\
\cline { 2 - 4 } & EQ & 0,95 & 0,83 \\
\cline { 2 - 4 } & CR & 0,96 & 0,81 \\
\hline \multirow{2}{*}{ A 2 } & WP & 0,92 & 0,77 \\
\cline { 2 - 4 } & EQ & 0,98 & 0,83 \\
\cline { 2 - 4 } & CR & 0,95 & 0,80 \\
\hline \multirow{3}{*}{ A 3 } & WP & 0,94 & 0,76 \\
\cline { 2 - 4 } & EQ & 0,97 & 0,80 \\
\cline { 2 - 4 } & CR & 0,9 & 0,80 \\
\hline \multirow{2}{*}{ A 4 } & WP & 0,93 & 0,78 \\
\cline { 2 - 4 } & EQ & 0,96 & 0,81 \\
\cline { 2 - 4 } & CR & 0,95 & 0,89 \\
\hline
\end{tabular}

\section{Normalization}

Originally TOPSIS utilized Euclidean distances. The best alternative should have the shortest distance from the ideal solution and the farthest distance from the anti-ideal solution. In our case, the separation measures from ideal level and anti-ideal level are computed through Minkowski’sdistance with $\mathrm{p}=1$. 
Considering the difficulty in comparing various criteria with different natures and different thresholds (Maximum performance and minimum performance for each criteria and each activity), this step was employed to normalize the scales of different selected criterion. In this case, the min-max normalization is introduced to scales the data from $\left(v_{i k}^{+} ; v_{i k}^{-}\right)$to $(0,1)$ in proportionas shown in Fig. 7. The advantages of this method can be concluded as:

1) It preserves all relationships of the data values exactly a since it carries out a linear normalization;

2) It does not introduce any potential bias into the data, and 3) it functions to nondimensionalize different indicator, further making them comparable [14] [25]. Aparameter $\lambda_{i c j} \in[0,1]$ is identified to normalize $\left(v_{i k j}\right)$ given by the following formula:

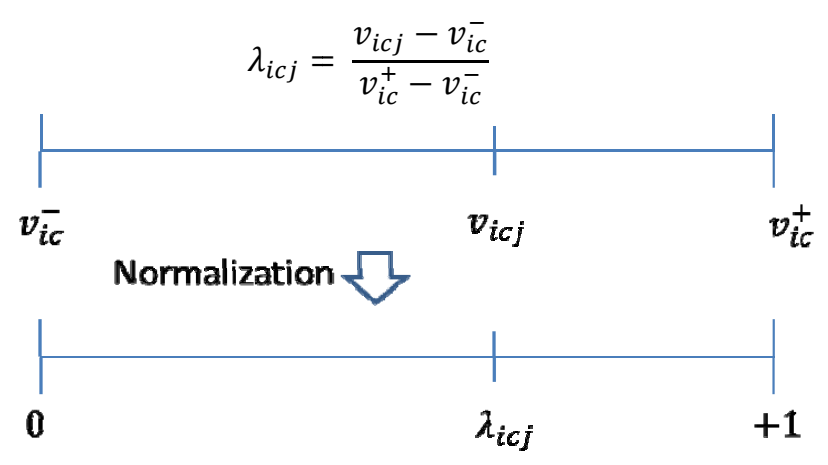

Fig. 7. The principal of normalization

The Table 11 presents the judgment matrix after normalization of the performance rating.

TABLE XI. Normalization of the performance rating

\begin{tabular}{|l|c|c|c|c|c|c|}
\hline$A_{I}$ & $A C_{c}$ & $T_{i c}$ & Op1 & Op2 & Op3 & Op4 \\
\hline \multirow{4}{*}{ A 1 } & $\mathrm{WP}$ & 0,9 & $\lambda_{111}=0,78$ & 0,28 & 0 & $\lambda_{114}=0,22$ \\
\cline { 2 - 7 } & $\mathrm{EQ}$ & 0,95 & 0,67 & 0 & 0 & 0,67 \\
\cline { 2 - 7 } & $\mathrm{CR}$ & 0,96 & 0,6 & 0 & 0,87 & 0,73 \\
\hline \multirow{4}{*}{ A 2 } & $\mathrm{WP}$ & 0,92 & 0,27 & 0,53 & 0 & 0,2 \\
\cline { 2 - 7 } & $\mathrm{EQ}$ & 0,98 & 0 & 0,47 & 0,67 & 0,47 \\
\cline { 2 - 7 } & $\mathrm{CR}$ & 0,95 & 0 & 0,6 & 0,13 & 0,47 \\
\hline \multirow{4}{*}{ A 3 } & $\mathrm{WP}$ & 0,89 & 0 & 0,39 & 1 & 1 \\
\cline { 2 - 7 } & $\mathrm{EQ}$ & 0,97 & 0,41 & 0 & 0,53 & 0,35 \\
\cline { 2 - 7 } & $\mathrm{CR}$ & 0,9 & 0 & 0,20 & 0,8 & 0,5 \\
\hline \multirow{4}{*}{ A 4 } & $\mathrm{WP}$ & 0,85 & 1 & 0,07 & 0 & 0,2 \\
\cline { 2 - 7 } & $\mathrm{EQ}$ & 0,96 & 0,8 & 0,07 & 0 & 0,4 \\
\cline { 2 - 7 } & $\mathrm{CR}$ & 0,95 & $\lambda_{431}=0$ & 0 & 1 & $\lambda_{434}=1$ \\
\hline
\end{tabular}

\section{E. Calculation of the relative closeness $P L_{j}$ and ranking}

For a compound competence, performance level $P L_{j} \in[0,1]$ is an indicator of the degree of excellence in the use of all individual competencies by worker (j) in execution of all activities. The value of performance level is calculated using the following formula:

$$
P L_{j}=\frac{D_{j}^{-}}{D_{j}^{+}+D_{j}^{-}}
$$

Where,

The distances from ideal level:

$$
D_{j}^{+}=\sum_{i=1}^{N} \varphi_{i} \sum_{c=1}^{L} \omega_{i c} \cdot D_{i c j}^{+} \quad, \forall j \in M
$$


The distances from anti-ideal level:

$$
D_{j}^{-}=\sum_{i=1}^{N} \varphi_{i} \sum_{c=1}^{L} \omega_{i c} . D_{i c j}^{-} \quad, \forall j \in M
$$

With:

$$
\begin{gathered}
D_{i c j}^{+}=1-\lambda_{i c j} \\
D_{i c j}^{-}=\lambda_{i c j} \\
\sum_{i=1}^{N} \varphi_{i}=1 ; \sum_{c=1}^{L} \omega_{i c}=1, \forall i \in N
\end{gathered}
$$

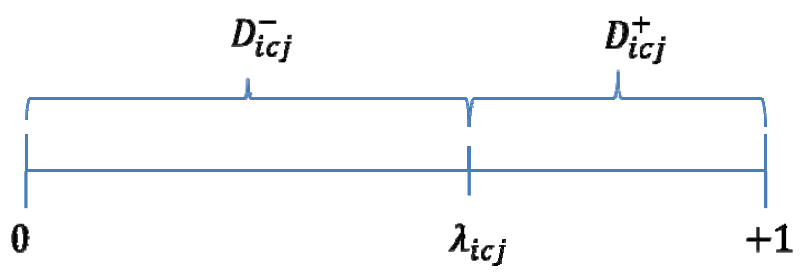

Fig. 8. The principal of distances calculation

Therefore,

$$
P L_{j}=\frac{D_{j}^{-}}{D_{j}^{+}+D_{j}^{-}}=\sum_{i=1}^{N} \varphi_{i} \sum_{c=1}^{L} \omega_{i c} \cdot \lambda_{i c j} \quad, \forall j \in M
$$

We need to calculate the relative closeness and rank workers in descending order. The larger is the index value; the better is the performance of the operator. The Table 12 and Fig. 9.present the relative closeness and ranking of operators with respect to the ideal performance level.

TABLE XII. The relative closeness and ranking

\begin{tabular}{|c|c|c|c|c|}
\cline { 2 - 5 } \multicolumn{1}{c|}{} & Op1 & Op2 & Op3 & Op4 \\
\hline D+ & 0,556 & 0,788 & 0,652 & 0,552 \\
\hline D- & 0,444 & 0,212 & 0,348 & 0,448 \\
\hline PL & 0,444 & 0,212 & 0,348 & 0,448 \\
\hline Rank & 2 & 4 & 3 & 1 \\
\hline
\end{tabular}

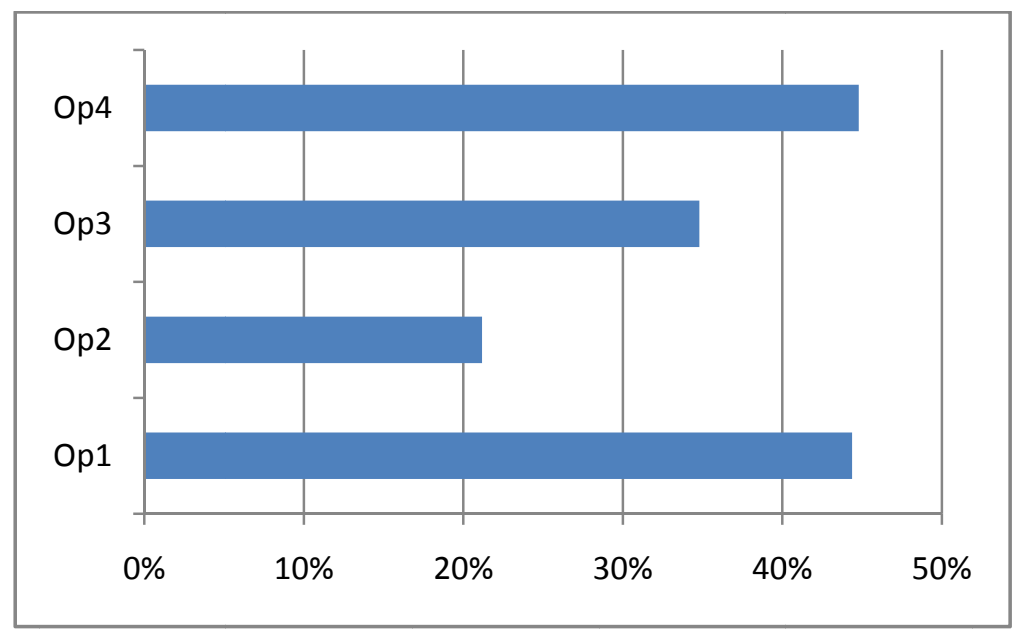

Fig. 9. The relative closeness and ranking

In this paper, wehave proposed a hybrid TOPSIS-AHP model for synthesizing priorities and rating values into a single integrated indicator. 


\section{CONCLUSION}

This approach seems more meaningful since it involves a decision process using AHP and TOPSIS techniques for assessment of multi-skilled workforce in an objective way. In themanufacturing industryhuman resources areconsidered as a keyelement of performance. In this context,wehave defineddifferent criteria and we have useddecision making techniquesto providean operational tool for assessment ofmulti-skilled workforce. In this paper, we have proposed a method using AHP technique and TOPSIS logic for classification of workers; we have expressed the worker's efficiency through tangible results. We have used AHP technique as decision support tool for weighting assessment criteria and activities. On the other hand, we have also used TOPSIS logic as a decision support tool for distance measuring between acquired levels and required levels. The model proposed in this study is meaningful for aggregation, simple to use for real-world applications and allows the companyto better determine theavailable performance levels of human resources they possess.

\section{REFERENCES}

[1] Beirendonck, L.V. (2006). Tout compétents ! Le management des compétences dans l'entreprise.

[2] Belenson, S.M., Kapur, K.C. (1973). An algorithm for solving multicriterion linear programming problems with examples, Operational Research Quarterly 24 (1) 65-77.

[3] Billet, C. (2005). Le Guide des techniques d’évaluation. Paris :Dunod.

[4] Boucher, X. , Burlat, P. (2003).Towards integration of skills in the performance management of the company, JESA, Vol. 37, No.3, pp. 363-390.

[5] De Bruecker, P., Van den Bergh, J., Belien, J and Demeulemeester, E. (2015). Workforce planning incorporating skills: state of the art, European Journal of Operational Research,vol.243,no.1, pp. 1-16.

[6] Défelix, C. (2003). Ce que gérer les compétences veut dire, Revue Economique et Sociale.

[7] Evereare, C. (2000). La compétence : un compromis multidimensionnel fragile, Gestion 2000, 17, 4, pp. 53-71.

[8] Fan Z.P., Feng B., Sun Y.H., Ou W., (2009-b). Evaluating knowledge management capability of organizations: a fuzzy linguistic method. Expert Systems with Applications, Vol. 36, pp. 3346-3354.

[9] Gérard, F.M., Van Lint-Muguerza, S. (2000). Quel équilibre entre une appréciation globale de la compétence et le recours aux critères ?, in BOSMAN,C., GERARD, F.M.

[10] Herrera E., (2012). Contribution à la Modélisation et Résolution du Problème d'Affectation sous Contraintes de Compétences et Préférences. Thèse de doctorat en Productique Génie Industriel, Université Paris 8, Vincennes-Saint-Denis, France.

[11] Hwang, C.L., Yoon, K. (1981). Multiple Attribute Decision Making, Springer-Verlag, Berlin.

[12] Janic, M. (2003). Multicriteria evaluation of high-speed rail, transrapid maglev, and air passenger transport in Europe, Transportation Planning and Technology 26 (6) 491-512.

[13] Kwong, C.K., Tam, S.M. (2002). Case-based reasoning approach to concurrent design of low power transformers, Journal of Materials Processing Technology 128 136-141.

[14] Li, W.J., Liu, Z.Y., 2011. A method of SVM with normalization in intrusion detection. Procedia Environmental Sciences 11, $256-262$.

[15] Milani, A.S. Shanian, A., Madoliat, R. (2005). The effect of normalization norms in multiple attribute decision making models: A case study in gear material selection, Structural Multidisciplinary Optimization 29 (4) 312-318.

[16] Nagels, Marc (2009). Evaluer des compétences ou des performances ? une distinction opérationnelle en gestion des ressources humaines, 21e colloque de l'ADMEE-Europe, 21-23 janvier 2009, p. 1, Manuscrit auteur, publié dans "Évaluation et développement professionnel, Louvain-La-Neuve : Belgique (2009)"

[17] Parlier, M., (1997). Les enjeux et les ambivalences de la gestion des compétences, Connexions 70-2.

[18] Pulakos, E. D. (2007). Performance Measurement. DansDeborah L. Whetzel et Georges R. Wheaton (Éds.), Applied Measurement. Industrial Psychology in Human Resources Management (pp. 293-318). Mahwah, New Jersey: Lawrence Erlbaum Associates.

[19] Rabardel P., Six B. (1995). Outiller les acteurs de la formation pour le développement des compétences au travail. Éducation permanente, $123(2)$

[20] Saaty, T.L., Ozdemir M.S., (2003). Why the magic number seven plus or minus two, Mathematical and Computer Modelling 38, 233244.

[21] Saaty Thomas L., Vargas Luis G., (2001). Models, Methods, Concepts \& Applications of the Analytic Hierarchy Process. Springer, ISBN-13: 9780792372677, ISBN: 0792372670.

[22] Scott, S.G. et Einstein, W.O. (2001). Strategic performance appraisal in team-basedorganizations: One size does not fit all. The Academy of Management Executive, 15(2), 107-116.

[23] Tai W.S., Chen C.T., (2009). A new evaluation model for intellectual capital based on computing with linguistic variable. Expert Systems with Applications, Vol. 36, pp. 3483-3488.

[24] Yoon, K., Hwang, C.L. (1985). Manufacturing plant location analysis by multiple attribute decision making: Part I-single-plant strategy, International Journal of Production Research 23, 345-359.

[25] Yu, Z., Fung, B., Haghighat, F., et al., 2011. A systematic procedure to study the influence of occupant behavior on building energy consumption. Energy andBuildings 43 (6), 1409-1417.

[26] Zaki A., Benchekroun B., Benbrahim M., Campagne J.P. (2014). Proposition of a Quantified Method for the Individual Competence Assessment in Manufacturing Industry. European Journal of Scientific Research Vol. 126 No 4 November,pp.329 - 342.

[27] Zeleny, M. (1974). A concept of compromise solutions and the method of the displaced ideal, Computers and Operations Research 1, 479-496. 